\title{
RISK FACTORS WITH ACUTE SPORTS INJURIES
}

\author{
S. SONNE-HOLM and C. H. SØRENSEN
}

Department of Orthopedic Surgery (T-3)

Copenhagen University Hospital, Gentofte, DK-2900 Hellerup, Denmark

When examining more closely the risk factors in acute sports injuries it is a prerequisite to know the epidemiology.

Previous studies may be divided into four groups according to the materials and methods used.

1. Hospital surveys have the advantage that all major injuries occurring within the hospital's area of admission will be registered. On the other hand, the estimation of the number of active athletes within the same area is often uncertain.

2. Investigations made by insurance companies are vitiated by selection bias, since the majority of insured athletes will be found among those topperformance athletes and among those participating in the types of sport that cause many injuries.

3. Studies based on interviews of active or formerly active athletes are vitiated by the inaccuracies usually inherent in epidemiological investigations with a retrospective design.

4. The ideal epidemiological study would be a continuous follow-up through several years of a randomly selected group of active athletes.

In most studies the incidence of injuries has been defined as the average number of injuries per athlete per year. If one wishes to calculate comparable incidences, it is necessary to include in the definition the amount of time an athlete is exposed to the risk of sustaining an injury. Obviously, a top-performance football player will spend more time on the ground than one who is just playing for the sake of exercise. Presumably, there is also

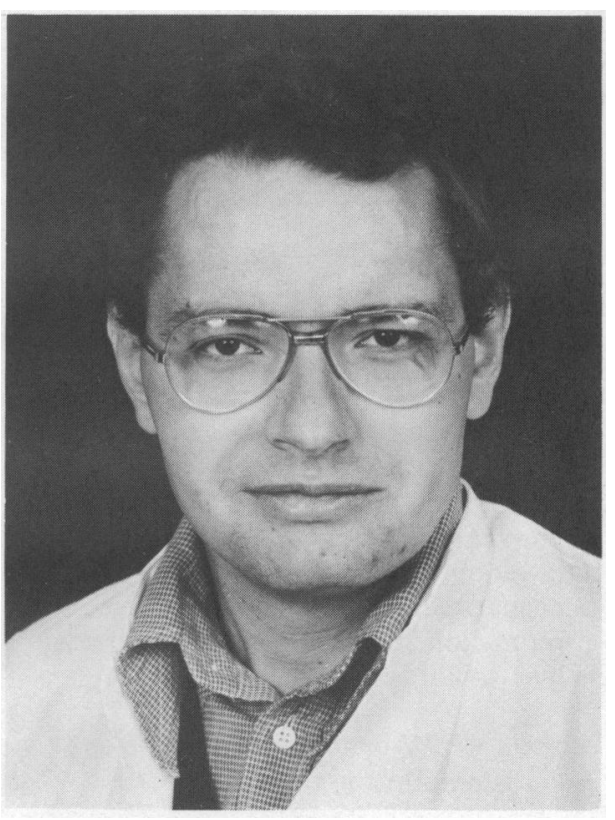

a difference in the number of hours spent by athletes who perform at the same level but in different types of sport.

Knowledge about the incidence of injuries is not sufficient to identify the most dangerous sports. It is necessary to classify the injuries according to severity and this may be done in several ways. Some investigators classify the injuries according to the type of injury, i.e. fractures, ruptures of ligaments, dislocations, and so on. This classification, however, appears irrelevant when the objective is to evaluate the consequences of the injuries.

The number of days lost through sickness (i.e. the disability days) is a more relevant dependent variable which may be treated statistically and which takes into account the athlete's occupation.

The number of treatments required is correlated to the type of injury but it does not specify long-term results.

Classification of the injuries according to social costs is important from an socio-economic point of view.

To investigate the risk factors within organized athletics, predictive variables include the type of sport, the level of performance, and competition versus training.

Dependent variables used were: the incidence of injuries, the distribution of sick days, and the frequency of treatment beyond the primary treatment in a casualty ward. 353 consecutive sports injuries were collected 
prospectively during a 6-month-period in a casualty ward in the Copenhagen county hospital, which covers a number of suburban districts with a total of 326,000 inhabitants. Only athletes who were active members of an athletic association were included in the investigation. $99 \%$ of the patients were traced and interviewed.

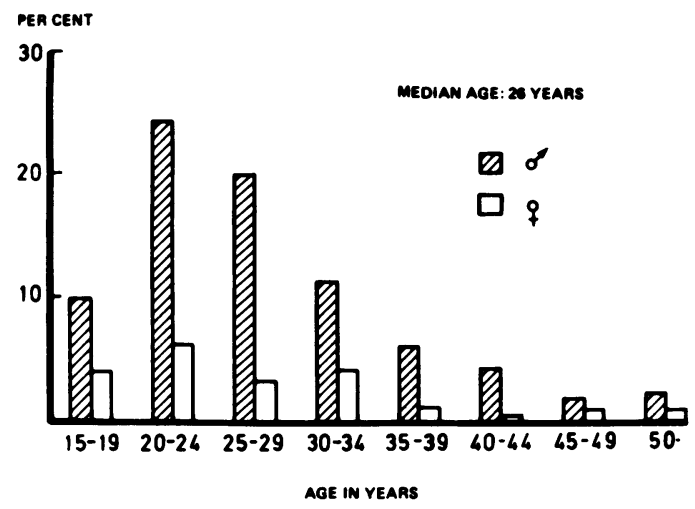

Fig. 1 Distribution of injuries according to age and sex.

Fig. 1 shows the percentage distribution of sex and age. The largest number of injuries, 30\%, appeared in the age group 20-24 years, median 26 years, sex ratio - male: female $=4: 1$. Number of injuries decreased with age, which reflects that the number of active athletes decreases with age.

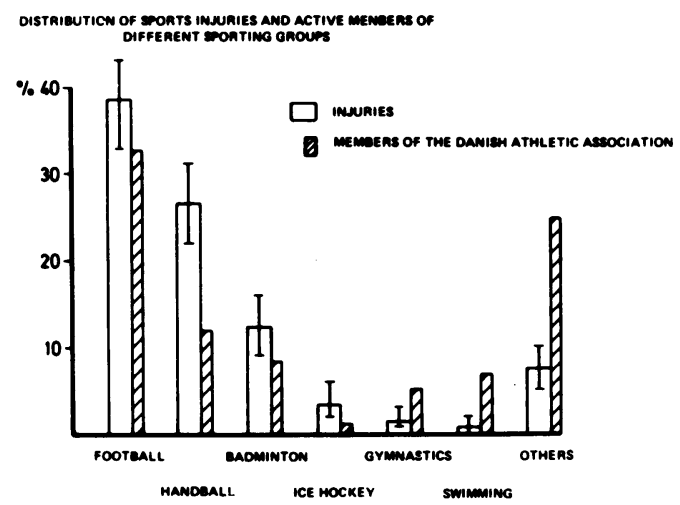

Fig. 2 Distribution of injuries according to activity.

Fig. 2: The distribution of injuries in different sports compared with the distribution of the members of the Danish Athletic Association. This gave an indirect estimate of the incidence.

The injuries are listed in the broad columns, members in the narrow columns. The parentheses indicate the 95\% confidence limits.

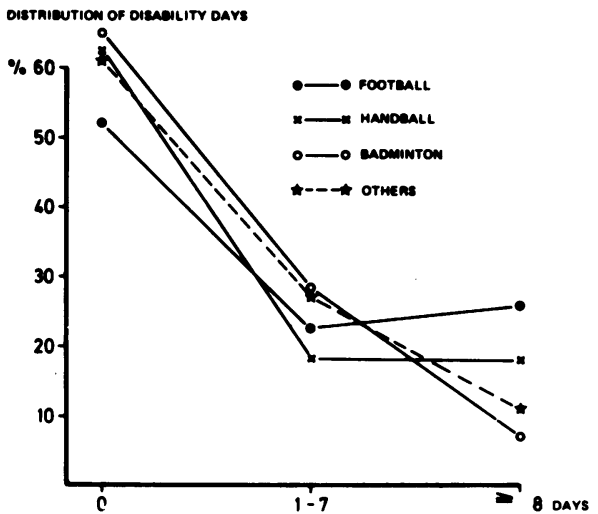

Fig. 3 Duration of injuries according to event.

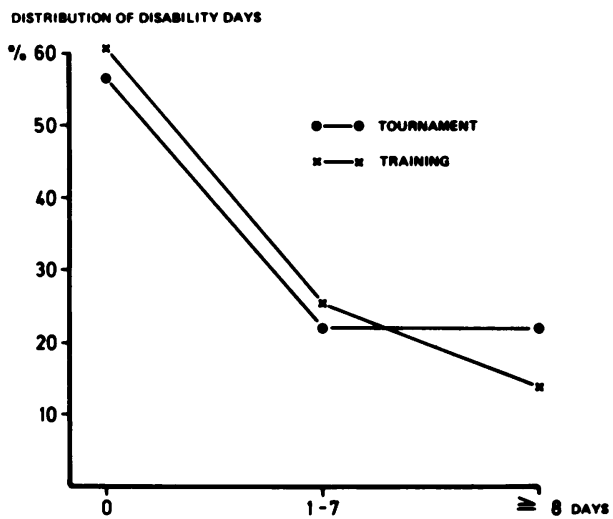

Fig. 4 Duration of incapacity, injuries sustained in training as opposed to those sustained in training.

\section{Days off work}

The most popular sports had more injuries than expected, especially handball. The number of participants was well below the lower confidence limit. Football players were just below the lower limit. Gymnastics and swimming had much fewer injuries than could be expected.

The distribution of sick days showed that football and handball had significantly more injured members with a long period of illness than other sports. About $25 \%$ of the injured football players were reported sick for more than 8 days, in contrast to about $8 \%$ of injured badminton players.

This might indicate that football players tend to have an occupation that causes the players to report sick 
when they have just a minor injury. This, however, was not the case - for the frequency of patients needing further treatment was likewise significant, indicating that the injuries were more serious. More than half of the injuries sustained by football players required further treatment, while only $23 \%$ of the badminton players needed re-examination.

A little less than $25 \%$ of the injuries were sustained at top-performance level, which implies that this level of sport is associated with a higher rate of injuries than expected. $15 \%$ of football injuries occurred in tournament matches which is 15 times more than expected.

Apparently, there was a difference in the necessity for further treatment, since about half of all injuries sustained in tournament matches had to be re-examined, while only $38 \%$ of injuries sustained while training required further treatment. Since the majority of tournament injuries were football injuries, this difference is not real. If correction is performed for the many football injuries the significant difference disappears.

\section{REFERENCES}

Christophe, K \& Leard, S.: J.Amer.Coll.Health Ass. 1970, 18, 210- 121.

La Cava, G.: J.Sports Med. 1961, 1, 1961.

Vuori, I. M., Aho, A. J. \& Karakorpi, T.: Duodecim 1972, 88, 700-711.

Wela, K.: Beitr.Orthop. 1970, 17, 444-453.

SOCIAL COSTS OF SPORTS INJURIES

C. H. SORENSEN MD and S. SONNE-HOLM

Department of Orthopaedic Surgery, Copenhagen University Hospital

Sports injuries figure prominently in the sickness statistics of young people and consequently have a negative socio-economic influence.

In Denmark, we have looked at (a) the social costs per sports injury in different sports, (b) the athlete's private loss per injury, and (c) Denmark's annual social costs of acute sports injuries.
For our calculations we have used a conventional model which divides the costs into:

1. The expenditure of the health services and the loss of production. Five weeks after the injury every athlete was asked about his further treatment, number of days lost through sickness, sick pay, and so on. Loss of production was calculated for each individual by 